\title{
A LDBEN 9394/96 e a ampliação das escolas de tempo integral no Brasil
}

Lúcia Velloso Maurício - Universidade do Estado do Rio de Janeiro (UERJ)

\section{Resumo}

Este texto foi pensado para o seminário promovido pela Fundação Darcy Ribeiro para comemorar os 20 anos de vigência da LDBEN. A mesa de que participei tinha como foco a seguinte questão: a LDB colaborou para a ampliação das escolas de tempo integral? Para respondê-la, recorri a textos do Senador Darcy Ribeiro elaborados entre 1991 e 1996, período de tramitação do projeto de lei no Congresso Nacional, para explicitar princípios caros ao professor Darcy Ribeiro, sua concepção de lei e de escola e por que propunha o tempo integral escolar. Finalizo o artigo com aspectos da proposta do Novo Ensino Médio, aprovada pela Lei 13.415/2017, que propõe tempo integral para o Ensino Médio, para destacar indícios de como esta proposta se distancia da concepção de Darcy Ribeiro para os Ginásios Públicos.

Palavras-chave:

Lei de Diretrizes e Bases da Educação Nacional (LDBEN); Tempo integral escolar; Darcy Ribeiro; Ginásios Públicos.

\section{The LDBEN 9394/96 and the expansion of the full-time school in Brazil}

\begin{abstract}
This text was first written for a seminar promoted by the Darcy Ribeiro Foundation to celebrate the 20th anniversary of the National Brazilian Education Law (LDBEN). My communication focused on the following question: did LDBEN collaborate to expand full-time schools? To answer this, I used essays written by Senator Darcy Ribeiro, between 1991 and 1996, during the period of the National Congress's debate do approve the bill, in order to explain dear principles to Professor Darcy Ribeiro, his conception of law and school and why he proposed full-time school. I conclude the paper with aspects of the proposal of New High School, approved by Law 13.415 / 2017, which proposes full time for High School, to highlight indications as to how this proposal distances itself from the conception of Darcy Ribeiro for Public Gymnasiums.
\end{abstract}

Key words:

National Brazilian Education Law (LDBEN); Full-time school; Darcy Ribeiro; Public Gymnasiums.

\section{A LDBEN 9394/96 e a ampliação das escolas de tempo integral no Brasil}

\section{0 anos da Lei de Diretrizes e Bases da Educação Nacional (LDBEN)}

A Lei de Diretrizes e Bases da Educação Nacional, Lei 9394/96 (BRASIL, 1996), conhecida como Lei Darcy Ribeiro em homenagem ao seu relator, completou 20 anos de vigência em dezembro de 2016. Na oportunidade, a Fundação Darcy Ribeiro decidiu comemorar a passagem da data realizando um evento ocorrido nos dias 25 e 26 de outubro de 2016, no Memorial 
Darcy Ribeiro, no Campus da UnB. Para abertura do evento, foi convidado o Professor Dr. Jamil Cury que proferiu a conferência Vinte Anos da Lei de Diretrizes e Bases da Educação NacionalLDBEN - (CURY, 2016).

Iniciou sua intervenção se colocando a pergunta: por que comemorar estes vinte anos da Lei.

Ela é uma oportunidade para se refletir sobre uma lei importante como um momento de recuo na história da educação, quanto de uma visada da situação atual. Pelo recuo é oportuno rever caminhos feitos, uma espécie de balanço e, abastecidos por este dobrar-se sobre si mesmo (re-flexão), pensar no quadro atual e em perspectivas desafiadoras que mantenha caminhos exitosos já trilhados, repense vias derreadas e anuncie vias novas. (CURY, 2016, p. 4)

Para fazer esta reflexão, a fim de enfrentar os desafios atuais e propor novas vias, a partir da revisão do trajeto percorrido pela LDBEN, também foram palestrantes a Professora Dra ${ }^{\mathrm{a}}$ Zaia Brandão, sobre a Educação Básica, e a Professora Dra ${ }^{\mathrm{a}}$. Isabel Lelis, sobre Formação de Professores, ambas da PUC-RJ, entre outros pesquisadores. A questão que perpassava as mesas propostas era discutir em que medida e de que forma a LDBEN tinha colaborado ou não para o desenvolvimento do tema de cada mesa. A mim, da UERJ, junto com Jacqueline Moll, da UFRS, coube discutir o tema da escola de tempo integral, que abordarei ao longo deste artigo.

Cury lembrou o processo longo e polêmico de tramitação dos projetos de LDBEN tanto na sociedade civil quanto no Congresso Nacional, desde 1988, no debate para a Constituição, até 1996, na promulgação da LDBEN, evidenciando, como tem ocorrido no Brasil, nossa dificuldade "quando o assunto é um marco regulatório da educação escolar". (IDEM, p.4). Do seu ponto de vista, coexistem concepções, ao mesmo tempo distintas e convergentes, uma coexistência entre o novo e o velho. Acrescentou que os dois projetos disputaram acirradamente a prevalência na LDBEN: o advindo do Senado, mais sintético, menos abrangente e mais restrito na sua elaboração; o originário da Câmara, mais analítico, mais abrangente que contou com ampla participação da sociedade civil, através dos Fóruns Estaduais e do Fórum Nacional em defesa da Escola Pública.

O termômetro capaz de medir a temperatura de ambos era dado pelo maior ou menor "calor" da intervenção do Estado na educação escolar, seja na administração pública, seja no segmento privado. E esse termômetro passou a subir tanto mais quanto mais o governo eleito em 1994 e empossado em 1995 não só fizera clara opção pelo projeto sintético, como aderiu à vaga conservadora de vários regimes políticos existentes, inclusive na América Latina (IDEM, p.11)

O autor enfatizou a quantidade de modificações que a LDBEN sofreu ao longo destes 20 anos: 87 alterações, o que corresponde a quase $90 \%$ do texto. Do seu ponto de vista, por mais que isto possa acontecer com qualquer lei, este fato é indicativo de que "algo poderia ter sido melhor 
redigido na versão original” (p.12). Comparou a tramitação do Plano Nacional de Educação (PNE) com a da LDBEN, afirmando que a trajetória do PNE, Lei $n^{\circ}$. 10.172/01, até sua aprovação “revelou a reedição da concepção de participação dos dois projetos (...) a rigor uma expressão continuada da LDBEN em matéria de metas, objetivos e financiamento".

Contudo, esse último ponto, ao ser sancionada a lei, sofreu vetos presidenciais. Eles significaram uma perda substantiva quanto ao caráter obrigatório do Plano podendo-se dizer que ele, praticamente, se tornou um Plano declaratório. (IDEM, p.13)

Cury considera que um dos maiores desafios do PNE, proposto pela LDBEN, é exatamente a sustentabilidade financeira. Destaca que a matéria já era complexa em tempos de estabilidade econômica, e que "em tempos de crise, além de complexa se torna complicada." Vai além, afirmando que a sustentabilidade financeira é condição para o sucesso do PNE e que "sua não efetivação será mais um retorno ao fracasso dos PNE passados (1936/37; 1961/62 e 20012011)" (IDEM p. 14). Em nota na mesma página, Cury revela preocupação com "momento crucial de nossa história política, na vigência de um governo de facto (não de jure)" pela perspectiva desalentadora de retorno da desvinculação dos recursos da União (DRU) e até de instrumentos piores. De lá para cá a DRU já foi aprovada, bem como o teto de gastos públicos por 20 anos, o que será trágico para a educação.

Para finalizar, Cury se pergunta se vale a pena propor o redesenho da LDB. Ele responde:

Com o Congresso que temos, com um governo de facto disposto a deformar o financiamento da educação, reabrir a LDB para refazê-la não seria abrir uma "caixinha de pandora"? Só uma política de Estado que presentifique o potencial da educação será capaz de superar as contradições e as barreiras que impedem a construção de uma democracia mais ampla. Se quisermos associar democracia e modernidade, ou o país como um todo toma a decisão inadiável e necessária de priorizar a educação básica como tarefa inadiável ou perderemos, todos, a velocidade da História. (IDEM p. 15)

\section{Educação em tempo integral: quais as possibilidades abertas pela LDBEN?}

A primeira mesa do evento tinha como tema a educação em tempo integral. De fato ela nos colocava - a mim, que participei da implantação dos CIEPs desde a 1 ${ }^{\mathrm{a}}$. Gestão do Governo Brizola, no I e no II Programa Especial de Educação; e a Jacqueline Moll, responsável, no Ministério de Educação, pela implantação do Programa Mais Educação, de 2008 a 2011, a seguinte questão: a LDB colaborou para a ampliação das escolas de tempo integral?

Para responder a esta pergunta, optei por recorrer a textos elaborados pelo Senador Darcy 
Ribeiro para contextualizar sua proposta de educação em tempo integral como está inscrita na LDBEN. Além da própria lei, na sua primeira versão, lancei mão de textos publicados sobre o projeto encaminhado ao Congresso e mesmo textos particulares a que tive acesso. Todos os textos foram elaborados entre 1991 e 1996, período de tramitação do projeto de lei no Congresso Nacional.

Antes de mergulhar nos textos, vale a pena lembrar que Darcy Ribeiro tinha tendência de polemizar os temas que lhe eram caros. Seus argumentos, muitas vezes considerados simplistas, não partiam de análise simplificadora da realidade, ao contrário; entretanto, na busca de convencer o leitor, carregava nas tintas das características que queria destacar, como uma caricatura. Seu objetivo era comunicar ao leitor a obviedade de determinadas marcas que sintetizavam o que ia por traz de muitos discursos e ações. Por isso mesmo ele alertava:

Não se iluda comigo, leitor. Além de antropólogo, sou homem de fé e de partido. Faço política e faço ciência movido por razões éticas e por um profundo patriotismo. Não procure, aqui, análises isentas. Este é um livro que quer ser participante, que aspira influir sobre as pessoas, que aspira ajudar o Brasil a encontrar-se a si mesmo. (RIBEIRO, 1995, p.17)

Após este alerta, vamos aos textos. O texto mais antigo, A lição de Lúcia, de janeiro de 1991, não tinha como objeto a própria lei. Analisava uma experiência de implantação de uma Escola de Demonstração, planejada e implementada por Darcy Ribeiro durante a $1^{\mathrm{a}}$. gestão do Governador Leonel Brizola, entre 1983 e 1986. Este texto oportunizou explicitar princípios, caros ao professor Darcy Ribeiro, que orientavam, reiteradamente, seus projetos na área de educação. Em primeiro lugar, que o erro é educativo e assim deve ser incorporado ao processo de fazimento: "Nada do que aqui se relata pode ser tido como exemplar no sentido de acerto incontestável. Tudo vale é como expressão de uma lúcida vontade de acertar, aceitando a inevitável margem de erro em que se incorre quem tenta acertar" (RIBEIRO, 1991, p.2). O segundo princípio é exatamente que o aprimoramento do processo se dá ao longo do fazimento: "Nada se ganharia, esperando de braços cruzados - senão a reiteração de uma rotina pobre - se eu não mandasse rodar, improvisando. Rodar da única forma que as coisas marcham no mundo real que é ir fazendo e corrigindo no curso do fazimento" (RIBEIRO, 1991, p. 3). O terceiro diz respeito à prática. O discurso por si só não forma, é necessário exercitar as artes do fazer:

Nossas faculdades de educação, integradas em universidades que jamais formariam médicos sem um hospital de clínicas, mas pretendendo formar professores sem qualquer experiência das artes da educação. Convertem a pedagogia numa série de discursos ocos, pretensamente educativos, sobre disciplinas científicas e humanísticas, supostamente indispensáveis à formação de um professor. (RIBEIRO, 1991, p.4) 
Os outros três textos têm relação intrínseca com o projeto de lei que tramitava no Congresso. Vou apresentá-los em ordem cronológica, mas os extratos de que me servirei não obedecerão a esta lógica, e sim ao tema que tentarei relacionar a alguns artigos da lei. Assim principiei pelo Discurso de apresentação do Projeto de Lei ao Senado, em maio de 1992 (RIBEIRO, 2003). Era um texto dirigido aos seus pares, com a intenção argumentativa. Era evidente a retórica para convencer os senadores do seu diagnóstico da educação brasileira e do seu projeto de lei como solução coerente com a análise apresentada.

O texto seguinte, Educação para a modernidade (RIBEIRO, 1992), foi publicado na Revista Carta ${ }^{\circ}$. 5, em dezembro de 1992. Esta revista constituiu uma publicação temática regular do Gabinete do Senador Darcy Ribeiro durante seu mandato. Este número tinha por tema a educação, tendo em vista o cumprimento de 60 anos da publicação do Manifesto da Educação Nova. Este texto, em contraponto aos textos históricos, abordava princípios orientadores para uma lei da educação adequada ao contexto brasileiro.

O texto A nova lei da educação (RIBEIRO, 1996) foi publicado na última edição da Revista Carta, $\mathrm{n}^{\text {o. }} 16$, em maio de 1996, tendo por tema a própria LDBEN. Era um curto texto introdutório, que comparava o projeto de LDBEN da Câmara com o substitutivo do Senado, de sua autoria. Esta edição $n^{0} .16$ foi distribuída a todos os deputados federais a quem era dirigido o prólogo, no sentido de sensibilizá-los contra duas emendas sobre a pós-graduação que seriam votadas na Câmara dos Deputados. Esta ação exemplifica o empenho do Senador Darcy Ribeiro, já gravemente doente, em defesa de suas conviç̧ões de que o Brasil é um país que pode dar certo e que a educação é fundamental neste processo.

\section{Concepção de lei}

Darcy Ribeiro repetiu reiteradamente sua compreensão sobre como deveria se constituir uma lei da Educação. Em maio de 1992, no discurso em que apresentou seu projeto ao Senado, ao sintetizar sua visão sobre a proposta de lei, concluiu, destacando a escola para o povo como condição para a autonomia da civilização brasileira, incluindo já, desde este momento, a necessidade de que a escola passasse a funcionar, progressivamente, em regime de tempo integral.

Assim é a lei que propomos, uma espécie de constituição que estabeleça os princípios gerais que regerão a reedificação educacional do Brasil, principalmente seu alicerce, que é a escola pública fundamental, formadora da cidadania e da força de trabalho. Nossa preocupação é estabelecer diretrizes e bases para a criação de uma escola fundamental, ajustada às condições da infância 
brasileira e capacitada para prepará-la para a cidadania, para o trabalho e para a solidariedade. Uma escola que, progressivamente, passe a funcionar em regime de tempo integral para os alunos e para os professores, a fim de dar ao Brasil condições efetivas de ingresso na futura civilização, como um povo dono de si mesmo, progressista e próspero. (RIBEIRO, 2003, p. 175 e 179)

No final do mesmo ano, insistia que o projeto não encarnava nenhum ideário avançadíssimo, era somente uma lei substantiva, funcional e simples, que permitiria ao Brasil realizar o que tantas nações do mesmo grau de desenvolvimento haviam alcançado há muitas décadas, no campo da educação. (RIBEIRO, 1992, p.10)

Em maio de 1996, após 4 anos de debates, já na tramitação final da LDBEN, o Senador Darcy Ribeiro procura buscar a adesão dos congressistas à sua proposta, argumentando sobre a pertinência de uma lei sucinta e ampla, condição para garantir a autonomia dos sistemas de ensino e das unidades educacionais que os compõem, preocupação materializada no artigo $8^{\circ}$. §2 $2^{\circ}$ - "Os sistemas de ensino terão liberdade de organização nos termos desta Lei.” (BRASIL, 1996); e no artigo $15^{\circ}$. - "Os sistemas de ensino assegurarão às unidades escolares públicas de educação básica que os integram progressivos graus de autonomia pedagógica e administrativa e de gestão financeira, observadas as normas gerais de direito financeiro público" (BRASIL, 1996). No texto de 1996, afirmava: "o substitutivo assume a forma de um diploma legal sucinto, claro e genérico, para dar espaço ao exercício da autonomia tanto por parte das escolas e universidades, como por parte de sistemas estaduais de ensino" (RIBEIRO, 1996, p. 11). Mais adiante, acrescentava: “a característica mais nobre de nosso substitutivo reside em sua ambição de assegurar a um tempo a unidade do sistema nacional de educação e a liberdade de variar, atendendo às especificidades dos estados e municípios” (RIBEIRO, 1996,p.13).

\section{Concepção de escola}

Na concepção de escola revelada pelo professor Darcy Ribeiro na apresentação do projeto de LDBEN no Senado, podem-se reconhecer princípios expressos no artigo $3^{\circ}$. da Lei, como a igualdade de condições para o acesso e permanência, na medida em que se propõe uma escola em que todos vão adquirir os domínios indispensáveis para continuar aprendendo; ou o princípio que garante padrão de qualidade, definido, no artigo $4^{\circ}$., como a variedade e quantidade de insumos indispensáveis ao processo de ensino-aprendizagem, tendo em vista o reconhecimento de que a generalização dos atributos de uma escola prática e eficiente vão atender a uma necessidade da Pátria. Assim se expressa Darcy Ribeiro: 
O que propomos, na verdade, não é mais a escola de educação comum para todos os cidadãos - que a Revolução Francesa pregou e a Revolução Norte-americana concretizou e que constitui, nas sábias palavras de Anísio Teixeira, "a maior das invenções humanas" - mas a escola universal que várias constituições brasileiras reclamaram, reiteradamente, mas que nunca conseguimos concretizar. Uma escola prática e eficiente, que não é preparatória a estudos posteriores, porque tem um fim em si mesma, que é dar a todos o domínio básico da leitura e do cálculo, a capacidade de continuar aprendendo, promover o desenvolvimento da inteligência, a formação do caráter e a preparação para viver solidariamente. A generalização destes atributos a todos os brasileiros de amanhã é direito do cidadão e necessidade da Pátria. Democracia, hoje, no Brasil significa, fundamentalmente, equidade no campo da educação, que é a chave da vida social e política e do trabalho. Quem lê vai adiante. $\mathrm{O}$ analfabeto já começa a vida fracassado. (RIBEIRO, 1992 p. 179/180)

Para fortalecer seu argumento junto aos pares no Senado, Darcy Ribeiro traça um diagnóstico da trajetória da infância no Brasil e indica o que a escola precisa oferecer para que este prognóstico não se consuma. Assim, sua concepção de escola é atravessada pela perspectiva de sua organização em tempo integral:

A verdadeira escola brasileira para milhões de brasileiros é a escola da rua, é a escola do lixo, é a escola do abandono, é a escola da criminalidade. Elas têm de ser substituídas pela única escola que funciona para o povo: a escola de tempo integral. Essas crianças pobres são o povo brasileiro em renovação. $\mathrm{O}$ que fizemos delas, faremos ao Brasil de amanhã. [...] Prevê-se também nesse projeto de lei a generalização da escola de tempo integral para alunos e para professores, coisa que Anísio Teixeira vem pedindo desde 1950, seja na forma da dupla escola parque $\mathrm{X}$ escola classe, seja na forma de centros integrados, mesmo porque só eles solucionam realmente o problema crucial da criança abandonada: o que é ela senão uma criança desescolarizada? (RIBEIRO, 1992, p. 181)

No final do ano (RIBEIRO, 1992), o Senador já estava convicto de que para a constituição de um sistema nacional de educação efetivo, alguns elementos seriam indispensáveis, como fixar as condições de espaço, tempo e qualidade do magistério necessárias ao sucesso escolar das classes populares. Concluía que estas condições implicavam na organização da escola de tempo completo como a que se oferecia nos países desenvolvidos, e que mesmo as sociedades mais individualistas asseguravam alimentação e outros serviços para que seus alunos pudessem aprender. Neste sentido, é natural que constasse nas disposições transitórias em que se propunha o estabelecimento da Década da Educação, no $87^{\circ}$. Artigo, o $§ 5^{\circ}$. “Serão conjugados todos os esforços objetivando a progressão das redes escolares públicas urbanas de ensino fundamental para o regime de escolas de tempo integral."

Em 1996, ao defender o substitutivo encaminhado pelo Senado, argumenta: 


\begin{abstract}
Nosso substitutivo abre também a possibilidade de que no Brasil, como ocorre em todo o mundo civilizado, se criem progressivamente escolas de tempo integral. Só elas são capazes de alfabetizar crianças oriundas de famílias pobres, que não tiveram escolaridade prévia. O pecado maior da pedagogia brasileira é seu pendor a responsabilizar a criança pobre por seu fracasso escolar. Este é culpa principalmente do nosso sistema escolar, que supõe que cada criança esteja alimentada, tenha material didático disponível e viva numa casa onde alguém possa ajudá-la nos estudos. Como a imensa maioria das famílias, inclusive nos Estados mais ricos, não tem essas condições, seus filhos são condenados à reprovação e ao fracasso na vida. (RIBEIRO, 1996, p. 12)
\end{abstract}

A preocupação de Darcy Ribeiro com a lógica da reprovação dos alunos pobres, oriundos de famílias não escolarizadas, já se expressava desde 1992, quando apresentou o projeto ao Senado. Vemos que seu argumento, citado abaixo, serviu de base para a formulação do artigo $23^{\circ}$. da LDBEN, que faculta aos sistemas de ensino a organização do processo de ensino-aprendizagem por ciclos:

A nova lei abre, também, aos sistemas estaduais de educação, a perspectiva de adotar a progressão contínua, impropriamente chamada de promoção automática. O que se faculta é deixar que o aluno passe de primeira para a segunda e até para a terceira série, ainda se alfabetizando, para que ele possa aproveitar todo o ensino oral e visual daquelas séries. Essa progressão significa, em essência, que ele não fica repetindo o mesmo aprendizado sempre na mesma primeira série, enquanto vê outras crianças se adiantarem (RIBEIRO, 2003, p. 180)

Chegamos assim ao artigo 34 que propõe: “A jornada escolar no ensino fundamental incluirá pelo menos quatro horas de trabalho efetivo em sala de aula, sendo progressivamente ampliado o período de permanência na escola." E no $\S 2^{\circ}$ : "O ensino fundamental será ministrado progressivamente em tempo integral, a critério dos sistemas de ensino" (BRASIL, 1996).

Cabem aqui duas observações importantes. Primeiramente o fato da proposta objetiva e clara de uma escola com tempo ampliado aparecer na Seção 3, no Capítulo II, do Título V, dedicada ao Ensino Fundamental. Por que não na Seção 1, das Disposições Gerais, do mesmo Capítulo e Título, tendo em vista a prevalência da escola de tempo integral na concepção de escola de Darcy Ribeiro? A resposta está no parágrafo $2^{\circ}$. do Artigo $5^{\circ}$. que estipula que "em todas as esferas administrativas, o Poder Público assegurará em primeiro lugar o acesso ao ensino obrigatório" (BRASIL, 1996). Na época da promulgação da LDBEN, a abrangência da obrigatoriedade escolar estava restrita ao Ensino Fundamental. Darcy Ribeiro era muito cioso do cumprimento de prioridades, como se pode constatar em suas propostas para outros níveis e 
modalidades de ensino. De fato, a proposta de tempo integral deveria ser alocada exatamente no nível prioritário, que era o Ensino Fundamental.

A segunda observação se desdobra em duas questões: por que se referiu à ampliação do período de permanência na escola no caput do artigo, em vez de propor tempo integral como aparece no parágrafo $2^{\circ}$. ou turno completo, como se vê em vários de seus textos já citados? Por que não determinou uma meta a ser atingida, já que se tratava de uma proposta para a faixa da obrigatoriedade escolar? $\mathrm{O}$ indício da resposta está no próprio parágrafo $2^{\circ}$. "a critério dos sistemas de ensino" (BRASIL, 1996). Já vimos a concepção que o Senador tinha do papel de uma lei da educação, quando apresentou seu projeto ao Senado "uma espécie de constituição que estabeleça os princípios gerais" (RIBEIRO, 1992, p. 179); ou 4 anos depois quando defendeu o substitutivo do Senado "um diploma legal sucinto, claro e genérico, para dar espaço ao exercício da autonomia por parte de sistemas estaduais de ensino" (RIBEIRO, 1996, p. 11). Darcy Ribeiro, em consonância com Anísio Teixeira que considerava que os objetivos da lei são muito gerais, mas os planos requerem maior precisão, entendia a lei como o estabelecimento de princípios e diretrizes; fixação de metas dizia respeito a planos de educação, como é indicado no final da LDBEN. Por outro lado, como antropólogo e conhecedor do interior do Brasil, tinha plena consciência da diversidade, possibilidade e limitações dos municípios brasileiros. O fato de algo estar na lei não é absolutamente garantia de que venha a se concretizar, mas aponta para este objetivo, como podemos constatar em alguns artigos da própria LDBEN. Por esta mesma compreensão, o caput do artigo se refere à jornada escolar com período de permanência sendo progressivamente ampliado. É um reconhecimento de que os sistemas de ensino vão caminhar em ritmos diversos para a efetivação do que, de fato, era a proposta do Senador, inserida no parágrafo segundo, o tempo integral no Ensino Fundamental.

No ano em que enviou o projeto ao Senado, em 1992, estava se desenvolvendo no Estado do Rio de Janeiro a $2^{\mathrm{a}}$. gestão do Governador Leonel Brizola que completou a implantação dos 506 CIEPs no estado. Darcy Ribeiro não assumiu a função de secretário de estado, como na 1a . gestão, exatamente porque estava no Senado com foco em algo essencial para todo o Brasil, a Lei da Educação. Mas acompanhou cada passo dessa implantação, como um laboratório experimental de como poderia se desenvolver a educação no país. Estava entusiasmado com a experiência, como se pode ver no seu discurso no Senado:

Toda uma revolução educacional está se realizando, hoje, debaixo de nossos olhos. Está em marcha a revolução pela qual nossos educadores lutam há 50 anos. Mas quase ninguém tem olhos de ver. É sintomático o fato de que os grandes jornais do mundo deram mais notícias, e notícias mais entusiásticas, desta revolução educacional, que a nossa mídia. Seria aceitável e até meritória sua 
crítica, se apresentassem um corpo de alternativas, se indicassem que este não é um bom caminho, porque o caminho seria outro, que se estaria prescrevendo. Mas não é assim. Simplesmente se rejeita, o que só se explica por estarem contentes com o Brasil tal qual é, e em matéria de educação, só quererem nos manter atados ao sistema educacional precaríssimo que temos e que condena nosso povo à ignorância e ao atraso. (RIBEIRO, 2003, p. 176)

Mesmo com este encantamento sobre a implantação da escola de tempo integral no estado do Rio de Janeiro, em proposta de centro integrado, não transportou para a lei qualquer modelo, prazo ou prescrição de como se deveria, ou se poderia, implantar a escola que considerava o caminho para a escolarização adequada à infância brasileira das classes populares. Restringiu-se ao artigo $34^{\mathrm{a}}$., já comentado, e à indicação, no artigo $87^{\circ}$. das disposições transitórias, da necessidade de se conjugarem esforços para a implantação de escolas de tempo integral.

\section{A LDB colaborou para a ampliação das escolas de tempo integral?}

Darcy Ribeiro afirmou muitas vezes, durante o processo de discussão da LDB no Congresso Nacional, que não é a lei que configura a realidade. Aspectos da realidade é que oportunizam princípios e diretrizes das leis. Assim eu me pergunto se Leonel Brizola e Darcy Ribeiro não tivessem feito a ousada proposta e implementação dos CIEPs no período da redemocratização, na década de 1980, durante o qual se discutia a nova constituição, se o artigo 34 estaria na LDBEN. Ainda me pergunto se Darcy Ribeiro não tivesse sido eleito senador no período de discussão da LDBEN no Congresso Nacional, enquanto se completava o projeto dos CIEPs na $2^{\mathrm{a}}$. gestão de Leonel Brizola, se o artigo 34 estaria na LDBEN.

Estes fatos políticos contribuíram para que a proposta de tempo integral se tornasse uma diretriz na LDBEN. Mas a base estava materializada em 506 CIEPs implantados no estado do Rio de Janeiro, tendo mobilizado mais de 20 mil profissionais da educação que neles trabalharam, alguns ainda trabalham, e mais de 200 mil alunos que passaram por estas escolas no período em que o I ou II PEE estavam em vigor, além de grande parte da população que matriculou seus filhos, netos e sobrinhos ou que foi tocado por esta escola porque ela existia no seu bairro e oferecia atividades de lazer para a comunidade escolar, ou porque trabalhou para sua construção física.

Esta concretude de escola e de fatos políticos marcou a LDBEN. Mas marcou com uma concepção. Como já apontado, os artigos $34^{\circ}$. e $87^{\circ}$. da lei se referem à escola de tempo integral, apesar da sinalização de que a ampliação progressiva da jornada escolar fica a critério dos sistemas de ensino. Mas tanto num artigo como no outro, o tempo integral ou a ampliação progressiva são 
propostos para a rede ou sistema de ensino. Não há qualquer referência à ampliação de jornada para os mais carentes. Esta poderia ser uma decisão de cada sistema de ensino como concepção de escola ou como prioridade de implantação. Em todos os textos citados de Darcy Ribeiro neste processo de discussão da LDBEN, quando se refere às classes populares ou às crianças pobres, afirma que a escola de tempo integral é aquela que é capaz de evitar que as mazelas sociais condenem as crianças brasileiras ao analfabetismo e à exclusão. Não é uma escola para os mais pobres, é uma escola para o Brasil.

Ana Cavaliere (2009) cunhou a expressão Escola de tempo integral versus aluno em tempo integral quando publicou um artigo assim intitulado na Revista em Aberto, em que discutia exatamente esta temática. De que estamos falando - de uma concepção de escola ou da ocupação de alunos carentes em tempo integral para evitar sua marginalidade? Darcy Ribeiro propunha uma escola que atendesse aos requisitos necessários para que o povo brasileiro tivesse seus direitos de educação e cidadania garantidos. Por decorrência de estar nesta escola, podia-se evitar talvez a exclusão social. Mas o que se propunha era uma escola adequada a realizar o processo civilizatório brasileiro.

O crescimento recente de matrículas em tempo integral no Brasil se caracteriza mais pelo formato aluno em tempo integral do que por uma escola em tempo integral, proporcionado fundamentalmente pelo Programa Mais Educação, criado em 2008. Sem dúvida o Programa reacendeu a discussão sobre a ampliação da jornada escolar, e naturalmente pôde se fundamentar nos artigos da LDBEN. Apesar da proposta do Programa apontar para uma reconfiguração da escola, suas condições de implementação não permitiam consolidar esta perspectiva, que era justificada pelo caráter indutor e não por uma política de ampliação da jornada escolar. Uma pesquisa realizada pela Fundação Itaú Social / Banco Mundial (2015) indicou as fragilidades do programa, entre elas, estar baseado em trabalho voluntário e se assentar em condições de infraestrutura precárias. Poderiam ser redirecionadas e corrigidas, certamente, como indica a pesquisa. Mas isto não mudaria o caráter do programa que não leva à constituição da escola de tempo integral. Há alguns municípios que negociaram as condições para a implantação do Programa nas suas escolas, porque já tinham em andamento ou em elaboração proposta de escola de tempo integral, como podemos citar em Palmas (TO), Sobral (CE) e Bonito (PE). Nestas condições, o Programa pode ser um facilitador da proposta de escola de tempo integral de Darcy Ribeiro.

Sintetizando, a lei por si só não é indutora do crescimento de escolas de tempo integral. É necessário observar o que está crescendo - escolas ou alunos em tempo integral. Há outros interesses que se fazem presentes, particularmente na ampliação da jornada escolar, com a Revista Interinstitucional Artes de Educar. Rio de Janeiro, V. 3 N.2 - pag 82-97 (jul/out2017): "Número Esperial Darcy Ribeiro" DOI: $10.12957 /$ riae.2017.31711 
contratação de serviços de empresas particulares para que o tempo possa ser ampliado ou, em circunstâncias mais graves, a contratação de pacotes completos com a formulação de projetos e oferecimento de atividades, em geral, direcionados aos alunos mais carentes, configurando uma proposta não mais educacional e sim assistencialista (MAURÍCIO, 2016). A LDBEN lançou uma diretriz promissora e os sistemas de ensino podem optar por buscá-la ou não. O Programa Mais Educação, com readequações, pode ser um colaborador para a ampliação das escolas de tempo integral. Mas é indispensável que se identifiquem os interesses que movem as propostas políticas, pois podem se distanciar em muito do que propuseram Anísio Teixeira e Darcy Ribeiro.

\section{O Novo Ensino Médio e o tempo integral escolar}

Para finalizar, abordo uma possível relação entre proposta de Darcy Ribeiro para a educação, que transparece na versão original LDBEN, e a proposta do Novo Ensino Médio, incorporada à LDBEN no decorrer deste ano, transfigurada de Medida Provisória (MP 746/ 2016) para lei (Lei 13.415/2017). Recentemente fui chamada a participar de uma mesa sobre Darcy Ribeiro e a reforma do Ensino Médio. O foco do seminário, de fato, era o Novo Ensino Médio, que, entre outras propostas, indica o tempo integral para este nível de ensino. Talvez porque o tempo integral escolar esteja associado a Darcy Ribeiro ou pela passagem dos 20 anos de seu falecimento, os organizadores da mesa tenham pensado na possível fertilidade de um debate que estabelecesse relação entre a proposta educacional de Darcy Ribeiro e o Novo Ensino Médio. Assim fui buscar nos fazimentos de Darcy Ribeiro elementos que pudessem alimentar um debate sobre esta especulação: o que diria Darcy Ribeiro sobre o Novo Ensino Médio?

Busquei estabelecer esta relação trazendo a público a proposta de Darcy Ribeiro para os Ginásios Públicos (GP), que vigorou de 1993 a 1994 na rede estadual do Rio de Janeiro, em prédios de CIEP, durante o II PEE ${ }^{1}$. Este projeto experimental, lançado antes da publicação da LDBEN, começou com 26 unidades e alcançou 68 ao final do II Programa Especial de Educação, oferecendo 40.800 vagas para alunos de $6^{\circ}$. ano em diante. Os Ginásios Públicos, com duração de 5 anos, previam oferecer um currículo integrado que atendesse aos alunos de $6^{\circ}$. ao $9^{\circ}$. anos do Ensino Fundamental e aos alunos de $1^{\circ}$. a $3^{\circ}$. anos do Ensino Médio, com opção pelo tempo integral escolar para os alunos que desejassem.

O projeto tinha por objetivo "a formação de um cidadão consciente dos seus direitos, capaz de atuar criticamente na construção e manutenção da democracia como fator maior; (...) capaz de compreender criticamente a realidade, fundamentado (...) em conhecimentos científicos para equacionar novas situações" (BARBOSA et. al, 1995, p.123). Adotava como diretrizes 
metodológicas: pensar, analisar, investigar e criar soluções, de forma a ler a realidade e sobre ela atuar, dando sentido às atividades desenvolvidas na escola; integrar necessariamente as disciplinas dos vários campos do saber, propiciando vivência cultural abrangente; abordar as artes como ampliação dos recursos de leitura da realidade e possibilidade de intervenção; desenvolver a educação física, para além da saúde, com valores de cooperação, solidariedade e respeito ao próximo; proporcionar oficinas, para os alunos que optavam pelo tempo integral (BARBOSA et al., 1995).

Selecionei dois aspectos da formulação do Novo Ensino Médio para confrontá-los com a proposta pedagógica dos GPs, que iluminou o texto inicial da LDBEN, para ilustrar como o projeto dos GPs caminha em sentido contrário daquele do Novo Ensino Médio.

Uma característica marcante do projeto do Novo Ensino Médio é a preparação para o trabalho. O Novo Ensino Médio inseriu, entre os chamados itinerários formativos, uma opção de formação técnica e profissional, na qual o aluno deixa de priorizar os campos de conhecimento que compõem os outros itinerários formativos, a saber, linguagens, matemática, ciências da natureza e ciências humanas, acompanhadas de suas tecnologias. A oferta desta formação técnica e profissional poderá considerar, a critério dos sistemas de ensino, "a inclusão de experiência prática de trabalho no setor produtivo" (BRASIL, 2017, art. 4º.). Esta formação também poderá se dar através de convênios com instituições de educação a distância, cuidando para sua comprovação, através de demonstração prática; de experiência de trabalho supervisionado adquirida fora do ambiente escolar; de atividades de educação técnica oferecidas em outras instituições de ensino; ou de cursos oferecidos por centros ou programas ocupacionais (BRASIL, 2017).

Percebe-se, pela configuração deste itinerário formativo, que seu objetivo em nada se aproxima da formação de um cidadão consciente dos seus direitos, capaz de atuar na construção da democracia, fundamentado em conhecimentos científicos para intervir na realidade, como queria Darcy Ribeiro para os GPs. Nos Ginásios Públicos, longe do setor produtivo e do trabalho supervisionado fora do ambiente escolar, as oficinas eram concebidas para apropriação de conceitos e habilidades trabalhados em sala de aula. Segundo a proposta, a oficina é um lugar em que se exerce um ofício para obtenção de um produto final. Não se tratava de profissionalização, mas de aplicação de conhecimentos à prática (BARBOSA et al., 1995). Nesta concepção, não é função da escola média profissionalizar. O aluno que tem um bom desempenho linguístico, que decodifica a matemática, que maneja a tecnologia, que compreende livros, manuais, instruções escritas, tabelas e gráficos, que entende seu papel na observação e experimentação, está apto a profissionalizar-se, pois é capaz de ajustar-se ao avanço da tecnologia (IDEM). 
Outro exemplo do distanciamento das propostas de educação de Darcy Ribeiro e o Novo Ensino Médio pode-se constatar no oferecimento da língua estrangeira. A LDBEN, na redação original do Artigo 36, estabelecia, entre suas diretrizes, que "Na parte diversificada do currículo, será incluída uma língua estrangeira moderna, como disciplina obrigatória, escolhida pela comunidade escolar, e uma segunda, em caráter optativo, dentro das disponibilidades da instituição" (BRASIL, 1996). O novo Ensino Médio introduziu no artigo 35-A § 4. a seguinte redação "Os currículos do ensino médio incluirão, obrigatoriamente, o estudo da língua inglesa e poderão ofertar outras línguas estrangeiras, em caráter optativo, preferencialmente o espanhol, de acordo com a disponibilidade de oferta, locais e horários definidos pelos sistemas de ensino" (BRASIL, 2017, art $3^{\circ}$.). A redação da LDBEN levava em consideração tanto a opção da comunidade escolar como a possibilidade da escola e da rede, indicando atenção à diversidade cultural e à variedade de recursos materiais e humanos dos municípios brasileiros. Esta preocupação se insere adequadamente nas diretrizes metodológicas do GP, que registra "criar soluções, de forma a ler a realidade e sobre ela atuar, dando sentido às atividades desenvolvidas na escola". Na medida em que a comunidade escolar é chamada a decidir, está buscando o objetivo de formar "um cidadão consciente dos seus direitos, capaz de atuar criticamente na construção e manutenção da democracia", lendo a realidade e atuando sobre ela.

Concluo este ensaio que lembrou o contexto de formulação da LDBEN há 20 anos atrás, deixando em nós o sentimento da falta que Darcy Ribeiro faz, após 20 anos do seu falecimento, mostrando a atualidade de sua concepção de educação ao indicar como a proposta do Novo Ensino Médio anda na contramão da história. Vale lembrar que Darcy Ribeiro, ao apresentar seu projeto de lei ao Senado, em 1992; ao defendê-lo diante da sua votação iminente, em 1996; e rascunhar seu projeto inicial de lei no processo de formulação da proposta dos Ginásios Públicos, teve no centro de sua argumentação o eixo da solidariedade, como citado abaixo, na ordem correspondente que aparece ao longo deste artigo:

...uma escola fundamental, ajustada às condições da infância brasileira e capacitada para prepará-la para a cidadania, para o trabalho e para a solidariedade (RIBEIRO, 1992).

Uma escola prática e eficiente, que não é preparatória a estudos posteriores, porque tem um fim em si mesma, que é dar a todos o domínio básico da leitura e do cálculo, a capacidade de continuar aprendendo, promover o desenvolvimento da inteligência, a formação do caráter e a preparação para viver solidariamente (RIBEIRO, 1996).

...propiciando vivência cultural abrangente; abordar as artes como ampliação dos recursos de leitura da realidade e possibilidade de intervenção; desenvolver a educação física, para além da saúde, com valores de cooperação, solidariedade e respeito ao próximo (GP). 
A falta que Darcy Ribeiro nos faz está na compreensão de que qualquer crise só poderá ser superada pela solidariedade. Como nos lembrou António Nóvoa, ao encerrar sua conferência no Rio de Janeiro no Educação 360, em setembro de 2016: "Não há atividade mais forte na pedagogia do que a cooperação. Devemos formar mutuamente uns aos outros. Já sabemos que os alunos aprendem mais entre si, o que não diminui em nada o nosso trabalho e a nossa responsabilidade, mas faz com que nos organizemos de uma maneira diferente" (NÓVOA, 2016) ${ }^{2}$.

\section{Referências Bibliográficas}

BARBOSA, Laurinda et al. Os Ginásios Públicos in GABINETE DO SENADOR DARCY RIBEIRO, Carta 15. Brasília: Senado Federal, 1995, p. 121-142.

BRASIL. Lei de Diretrizes e Bases da Educação Nacional (LDBEN) no 9394/96, de 20 de dezembro de 1996. Diário Oficial [da] República Federativa do Brasil, Poder Executivo, Brasília, DF, 23 de dez. de 1996, p. 27.833.

. Lei 10.172 de 10 de janeiro de 2001. Diário Oficial [da] República Federativa do Brasil, Poder Executivo, Brasília, DF, 10 de jan. De 2001, p.1.

. Lei 13.415, de 16 de fevereiro de 2017. Diário Oficial [da] República Federativa do Brasil, Poder Executivo, Brasília, DF, p. 1, 17 de fev. de 2017.

. Medida Provisória 746, de 23 de setembro de 2016. Diário Oficial [da] República Federativa do Brasil, Poder Executivo, Brasília, DF, p.1, Edição Extra, 23 de set. de 2016.

CAVALIERE, Ana Maria Villela. Escolas de Tempo Integral versus Alunos em Tempo Integral. In: MAURÍCIO, Lúcia Velloso. Em Aberto, Brasília, v. 22, n. 80, p. 51-64, abr. 2009.

CURY, Jamil. Vinte Anos da Lei de Diretrizes e Bases da Educação Nacional (LDBEN) in Jornal de Políticas Educacionais v.10, n.20, p. 03-17, Julho-Dezembro de 2016.

FUNDAÇÃO ITAÚ SOCIAL / BANCO MUNDIAL. Relatório de avaliação econômica e estudos qualitativos - O Programa Mais Educação, 2015. Acesso in http://www.redeitausocialdeavaliacao.org.br/wp-content/uploads/2015/11/relat_Mais _ Educa\%C3\%A7\%C3\%A3o_COMPLETO_20151118.pdf

MAURÍCIO, Lúcia Velloso. Condiçoes e interesses pela educação em tempo integral no Brasil in Revista de Educação e Cultura Contemporânea, vol. 13, n. 33, p. 84-100, 2016.

RIBEIRO, Darcy. A lição de Lúcia, Rio de Janeiro: inédito, 1991. Educação para a modernidade in GABINETE DO SENADOR DARCY RIBEIRO, Carta 05. Brasília: Senado Federal, p. 9-12, 1992. 
. O povo brasileiro: a evolução e o sentido do Brasil. São Paulo: Companhia das Letras,

1995.

. A nova lei da educação in GABINETE DO SENADOR DARCY RIBEIRO, Carta

16. Brasília: Senado Federal, p. 7-14, 1996.

. A lei da educação in SIMON, Pedro, Darcy Ribeiro. Brasília: Senado Federal, p. 171-

202, 2003.

${ }^{1}$ Os prédios de CIEP construídos no município do Rio de Janeiro que foram finalizados e inaugurados no I PEE (1983-1986) pertencem à administração municipal. Os prédios de CIEP finalizados e inaugurados no município do Rio de Janeiro no II PEE (1991-1994) pertencem à administração estadual.

${ }^{2}$ Jornal O Globo, 25/09/2016, p. 45. 